\title{
The effect in the film thickness reducing mechanism of functional groups in porous carbon sulfuric acid supercapacitor
}

\author{
Yue Liu ${ }^{1,2}$ (D) Yanshuai $\mathrm{Li}^{1} \cdot$ Qingyang Sun ${ }^{1} \cdot$ Yong Wang $^{1} \cdot$ Xiaojin Zhang $^{1} \cdot$ Dongfang Wang ${ }^{1} \cdot$ Wei Dong $^{1}$. \\ Shaobin Yang ${ }^{1}$
}

(c) Springer Nature Switzerland AG 2019

\begin{abstract}
In this paper, the different types and number of functional groups in porous carbon-carbon pore channels are discussed in the thinning mechanism of ionic solvent thin films, which has a significant impact on the absorption of $\mathrm{H}_{2} \mathrm{SO}_{4}$ electrolyte based Electric Double Layer Capacitors (EDLC). By exploring the binding energy of $-\mathrm{OH},-\mathrm{COOH},-\mathrm{SO}_{3} \mathrm{H},-\mathrm{NO}_{2}$ and other four functional groups with sulfuric acid and hexahydrate sulfuric acid of porous carbon channel and hexahydrate sulfuric acid, it was found that $-\mathrm{OH}$ had no repulsive effect on the cathode of the battery, and $-\mathrm{COOH},-\mathrm{SO}_{3} \mathrm{H},-\mathrm{NO}_{2}$ and other functional groups had obvious repulsive effect on the cathode of EDLC with the increase of the functional groups number, that is, there was an effect of increasing the capacitance of EDLC by increasing the number of sulfide molecular. This will excavate the potential electrode material in the practical application.
\end{abstract}

Keywords Supercapacitor · Functional groups · Film thickness reducing mechanism · Porous carbon

\section{Introduction}

The high speed development of super capacitor has attracted a lot of attention, but it still cannot fully meet the growing demand of the applications where high energy density is required. Since the energy density $(E)$ of super capacitor is proportional to the capacitance $(C)$ and the square of the voltage $(\mathrm{V})$, that is: $\mathrm{E}=0.5 \mathrm{CV}^{2}$, increasing either or both of the capacitance and the cell voltage is an effective way to increase the energy density. Although it is relatively simple to fabricate the individual components (e.g., electrode materials, electrolytes and structures) of the ESs, their interaction must be considered to promote the synergistic effect. For example, design and preparation of the porous carbon electrode materials should consider the matching between the pore structure and the size of the electrolyte ions in order to make a high capacitive electrode. The challenge is to produce high-performing electrolytes in the electrodes [1-3].
Developing new electrolytes/solutions with wide potential windows should be given even higher priority efforts than the development of new electrode materials. For example, aqueous electrolyte-based super capacitor usually have an operating potential window of about $1.0-1.3 \mathrm{~V}$ because the aqueous electrolyte's potential window is about $1.23 \mathrm{~V}$ (the potential window of $\mathrm{H}_{2} / \mathrm{O}_{2}$ evolution reactions at $1.0 \mathrm{~atm}$ and room temperature), while the organic electrolyte-based and ionic liquid (IL) based super capacitor generally have potential windows of 2.5-2.7 and 3.5-4.0 V, respectively. Normally, aqueous electrolytes exhibit high conductivity (for example, about $0.8 \mathrm{~S} / \mathrm{cm}^{2}$ for $1 \mathrm{M} \mathrm{H}_{2} \mathrm{SO}_{4}$ at $25^{\circ} \mathrm{C}$ ), which is at least one order of magnitude higher than that of organic and IL electrolytes [4-7].

Among different acidic electrolytes, $\mathrm{H}_{2} \mathrm{SO}_{4}$ is the most commonly used acid electrolyte for aqueous-based ESs mainly due to its very high ionic conductivity $\left(0.8 \mathrm{~S} / \mathrm{cm}^{2}\right.$ for $1 \mathrm{M} \mathrm{H}_{2} \mathrm{SO}_{4}$ at $\left.25^{\circ} \mathrm{C}\right)$.the specific capacitance increased with increasing electrolyte conductivity $[8,9]$.

$\triangle$ Yue Liu, yue.liu@unipd.it | ${ }^{1}$ College of Materials Science and Engineering, Liaoning Technical University, Fuxin 123000, China. ${ }^{2}$ Department of Physics and Astronomy, University of Padova, 15131 Padua, Italy.

SN Applied Sciences (2019) 1:167| https://doi.org/10.1007/s42452-019-0171-7 
For instance, the matching between the electrolyte ion size and the pore size of carbon electrode material has a profound influence on the achievable specific capacitance. The super-capacitor is paying attention on the specific surface area and the distance between the $\mathrm{C}$ and electrolyte of $\mathrm{H}_{2} \mathrm{SO}_{4}$, this could increase the capacity obviously [10]. Aqueous $\mathrm{H}_{2} \mathrm{SO}_{4}$ electrolyte also included some pseudocapacitance contributions besides the electrostatic EDL capacitance. This was attributed to the fast redox reactions which occurred on the particular surface functionalities, such as oxygenated carbon species. This pseudocapacitance could be further enhanced by introducing heteroatoms (e.g., oxygen, nitrogen, and phosphorous) or certain surface functional groups (e.g., anthraquinone) to the carbon material surfaces.

The $\mathrm{H}_{2} \mathrm{SO}_{4}$ electrolyte-based EDLCs have higher specific capacitances when compared to those of organic electrolyte-based ones, even using the same electrode materials. This may reflect the different interactions between the electrode materials and the electrolytes induced by different electrolytes [11-13].

The honeycomb like porous carbon with $\mathrm{KOH}$ electrolyte activation could form maximum energy density [14, 15], which is a reference for the $\mathrm{H}_{2} \mathrm{SO}_{4}$ electrolyte. The ionic solvent film thickness reducing mechanism need to absorb more ions such as $\mathrm{SO}_{4}{ }^{2-}$ and expel water to gain the conductivity [16].

In this paper, the different sort and numbers of functional group in the carbon pores was discussed in the film thickness reducing mechanism, which influence the absorption of the $\mathrm{SO}_{4}{ }^{2-}$ and further the capacitor obviously.

\section{Simulations}

A porous carbon model (with a radius of $8 \mathrm{~nm}$ and a length of $1.28 \mu \mathrm{m}$ ) was designed by using the three-dimensional molecular structure software of Chem $3 \mathrm{D}$, and the binding energy of the molecular configuration was calculated using the software MM2. Because the functional groups usually exist on the carbon surface, their effects on the capacitance must be considered because they are involved in the Faradic pseudocapacitance effect, which significantly increases the specific capacitance of the carbon in the acid base supercapacitor $[17,18]$. The purpose of this study is to understand the binding of different types and numbers of functional groups on the porous carbon channel sulfate radical batteries, and to analyze the effect of the functional groups on the thinning of the films, and to find out the best types and the number of functional groups. The flow diagram is shown in Fig. 1.

Molecular dynamics calculations of sulfate radicals and hexahydrate sulfate radicals in porous carbon channels with four functional groups $-\mathrm{OH},-\mathrm{COOH},-\mathrm{SO}_{3} \mathrm{H}$, and $-\mathrm{NO}_{2}$ have been carried out. Firstly, the basic energies of porous carbon, sulfate radical and various groups are calculated, and the data are shown in Table 1. The final binding energy is equal to the calculated ultimate energy minus the basic energy sum of each basic structure.

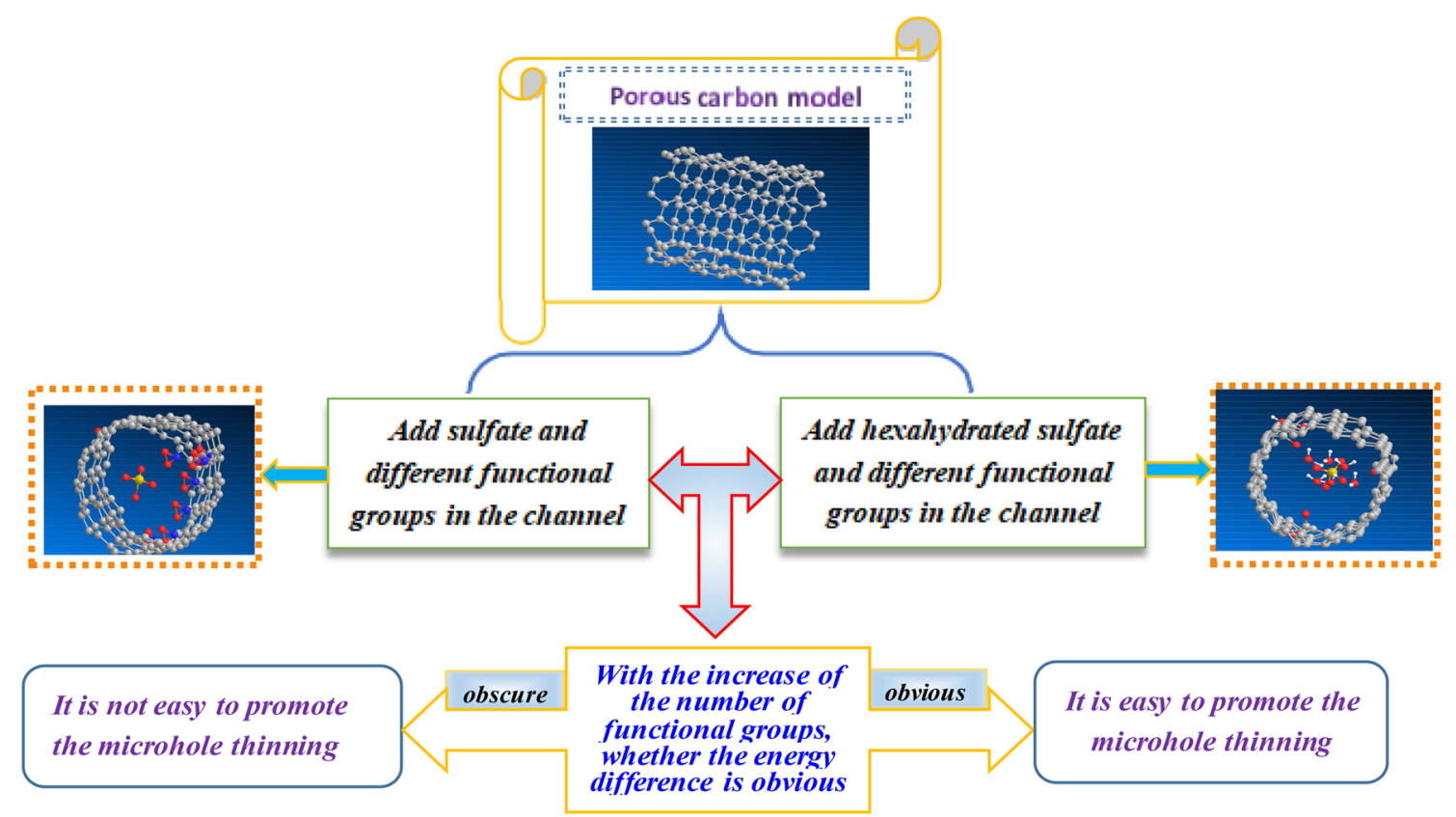

Fig. 1 Schematic diagram of process

SN Applied Sciences 
Table 1 Basic energy of basic structure

\begin{tabular}{llllllll}
\hline Basic structure & Porous carbon & $\mathrm{SO}_{4}{ }^{2-}$ & $\mathrm{H}_{2} \mathrm{O}$ & $-\mathrm{OH}$ & $-\mathrm{COOH}$ & $-\mathrm{NO}_{2}$ & $-\mathrm{SO}_{3} \mathrm{H}$ \\
\hline Basic energy kj/mol & 1205.26 & 1.80 & 0.12 & 0.08 & -1.14 & 0.21 & 1.43 \\
\hline
\end{tabular}

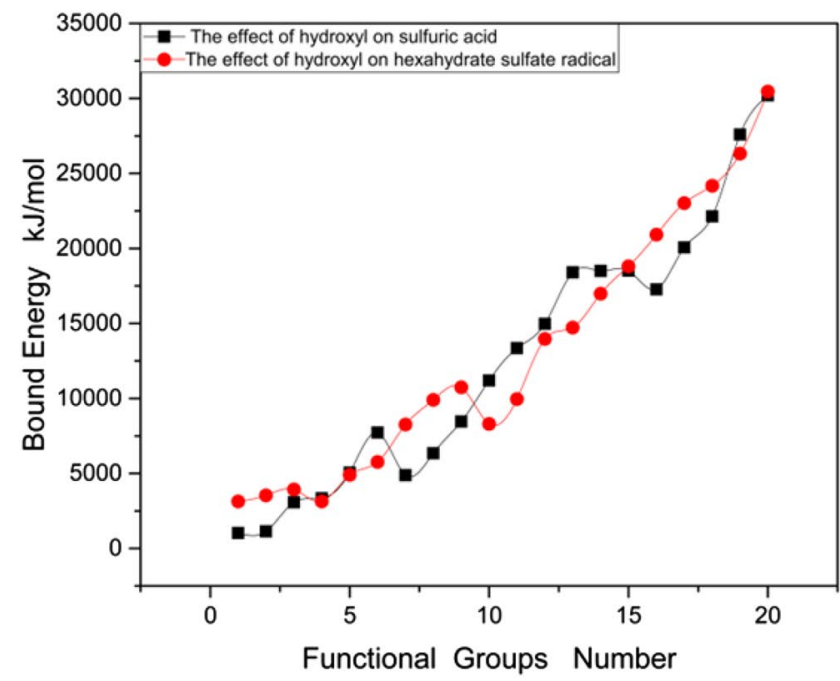

(a)

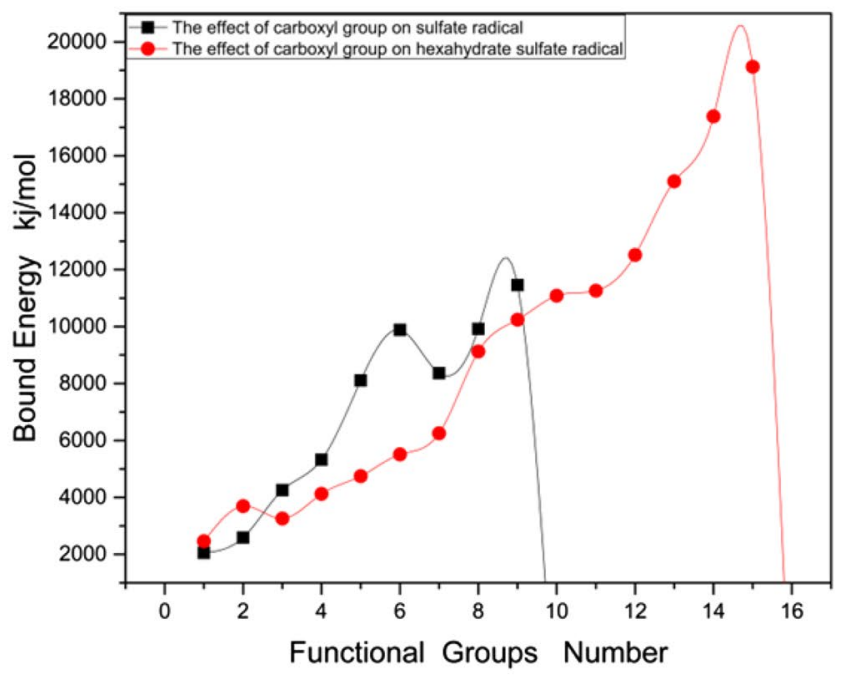

(b)

Fig. 2 Effect of $-\mathrm{OH}$ and $-\mathrm{COOH}$ on $\mathrm{SO}_{4}{ }^{2-}$ and theirs effect on $6 \mathrm{H}_{2} \mathrm{O} \cdot \mathrm{SO}_{4}^{2}$. a Effect of $-\mathrm{OH}$ on $\mathrm{SO}_{4}{ }^{2-}$ and its effect on $6 \mathrm{H}_{2} \mathrm{O} \cdot \mathrm{SO}_{4}{ }^{2}$. $\mathbf{b}$ Effect of $-\mathrm{COOH}$ on $\mathrm{SO}_{4}{ }^{2-}$ and its effect on $6 \mathrm{H}_{2} \mathrm{O} \cdot \mathrm{SO}_{4}{ }^{2-}$

\section{Results and analysis}

The experimental data were characterized by calculation and analysis. The effect of $-\mathrm{OH}$ and $-\mathrm{COOH}$ on sulfate radical and hexahydrate sulfate radical is shown in Fig. 2. According to Fig. 2a, It is found that $-\mathrm{OH}$ has no obvious effect on the thin film thinning mechanism of this type of battery. The reason for this result is that $-\mathrm{OH}$ and its structure form hydrogen bonds, and it is different to separate them with water. So with the increase of the number of bonding capacity is increasing, there is no effect to improve the high energy density of supercapacitors.

Figure $2 b$ shows the effect of $-\mathrm{COOH}$ on these two environments. It can be found that with the increase of the number of carboxyl groups, there is a repellent effect on sulfate radicals. This phenomenon is due to the hydrophilicity of the carboxyl group, and the formation of hydrogen bonds with sulfate hexahydrate, improve the binding energy. Therefore, more carboxyl groups are needed to destroy the stability of the binding, and the thinning effect of the functional groups on the cathode film will appear.

Figures 3 and 4 show the effect of $-\mathrm{NO}_{2}$ and $-\mathrm{SO}_{3} \mathrm{H}$ on $\mathrm{SO}_{4}{ }^{2-}$ and $6 \mathrm{H}_{2} \mathrm{O} \cdot \mathrm{SO}_{4}{ }^{2-}$ with similar effect, and the thin film thickness reducing effect under the condition of hexahydrate sulfate is more remarkable than the

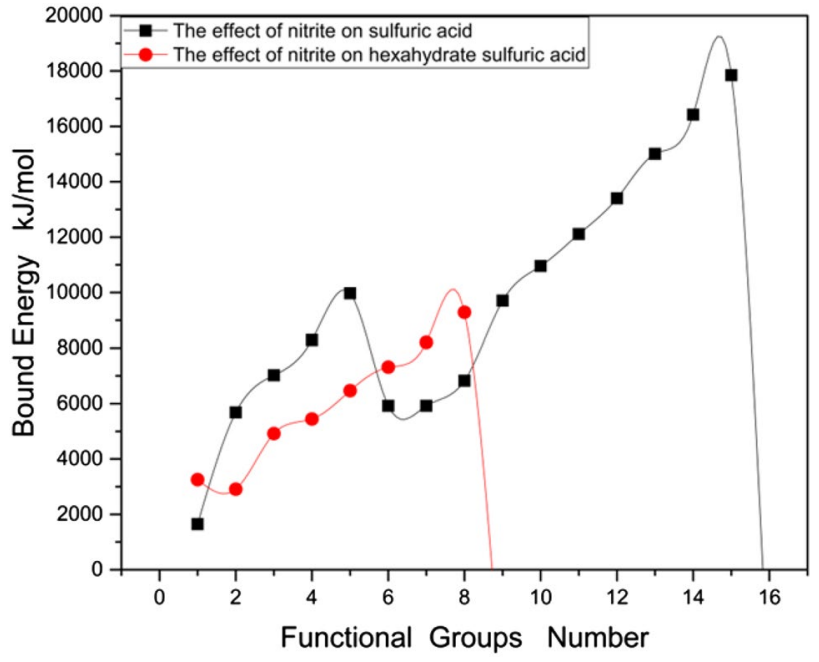

Fig. 3 Effect of $-\mathrm{NO}_{2}$ on $\mathrm{SO}_{4}{ }^{2-}$ and its effect on $6 \mathrm{H}_{2} \mathrm{O} \cdot \mathrm{SO}_{4}{ }^{2-}$

condition of simple sulfate. This is because $-\mathrm{NO}_{2}$ and $-\mathrm{SO}_{3} \mathrm{H}$ interact with the water in the sulfate hexahydrate, the elements involved in the binding increase, and the repulsion rate of sulfate increases, thus achieving the effect of thinning the cathode film and increasing the capacitance. It is found in Fig. 3 that when the number of functional groups $-\mathrm{NO}_{2}$ reaches more than 8 , the water molecules of the solvent film are strongly repulsed, 


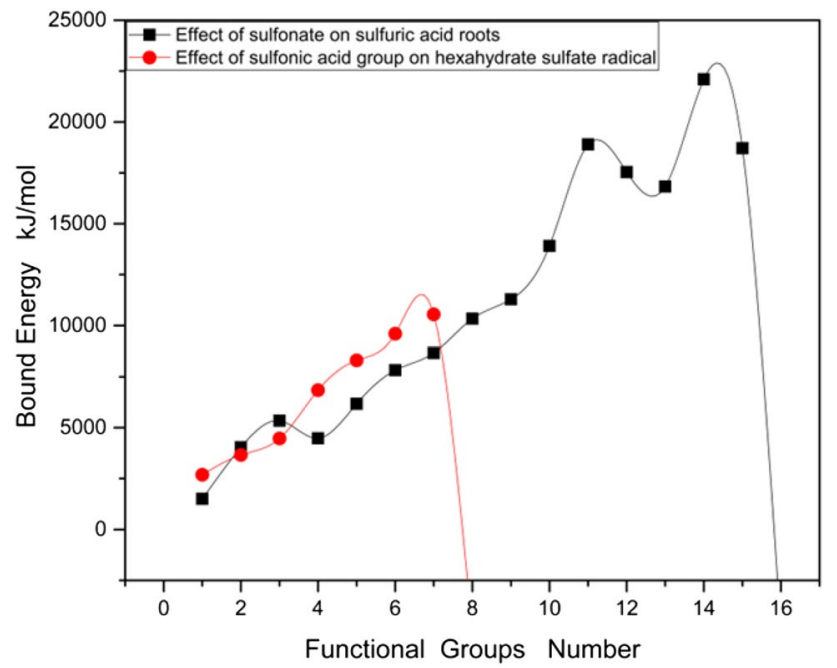

Fig. 4 Effect of $-\mathrm{SO}_{3} \mathrm{H}$ on $\mathrm{SO}_{4}{ }^{2-}$ and its effect on $6 \mathrm{H}_{2} \mathrm{O} \cdot \mathrm{SO}_{4}{ }^{2-}$

which can effectively improve the thinning effect of the solvent film. In Fig. 4, when the number of functional groups $-\mathrm{SO}_{3} \mathrm{H}$ reached more than 7 , the water molecules of the solvation film began to repel strongly, which can effectively improve the thinning effect of the solvation film. Therefore, $-\mathrm{NO}_{2}$ and $-\mathrm{SO}_{3} \mathrm{H}$ have good application prospects for the sulfate battery of solvent molecules. And the molecular dynamics simulation meet the experiment results, that $\mathrm{He}$ et al. Proved that $-\mathrm{NH}_{2}$ and $-\mathrm{SO}_{3} \mathrm{H}$ group enhanced the battery behavior obviously [19].

\section{Conclusion}

To sum up, this paper studies a new way to improve the high energy density of Supercapacitor. In the porous carbon model sulfate battery with a radius of $8 \mathrm{~nm}$ and a channel length of $1.28 \mu \mathrm{m}$, the binding effect of different types and number functional groups on the sulfate radical battery of porous carbon materials was analyzed by thin film thinning mechanism. It was found that $-\mathrm{OH}$ had no repellent effect on the water molecules of the cathode, and $-\mathrm{COOH},-\mathrm{SO}_{3} \mathrm{H},-\mathrm{NO}_{2}$ had obvious repellent effect on the water molecules of the cathode, and the film thickness decreased. That is to say, there is an increase in the effect of the battery capacitor. This method opens up new opportunities for designing high performance porous carbon electrode materials for Supercapacitor.

Author's contribution Prof. SY and WD contributed the original idea of this paper, YL and QS built the model, YW, XZ and DW analysed the data, and $Y L$ reorganized the idea and write the paper.

Funding This study was funded by Natural Science Foundation of Liaoning Province (20180551165).

\section{Compliance with ethical standards}

Conflict of interest The authors declare that they have no conflict of interest.

\section{References}

1. Zhong C, Deng Y, Hu W et al (2015) A review of electrolyte materials and compositions for electrochemical supercapacitors. Chem Soc Rev 44(21):7484-7539

2. Jana M, Khanra P, Murmu NC et al (2014) Covalent surface modification of chemically derived graphene and its application as supercapacitor electrode material. Phys Chem Chem Phys 16(16):7618-7626

3. Deng L, Wang J, Zhu G et al (2014) $\mathrm{RuO}_{2}$ /graphene hybrid material for high performance electrochemical capacitor. J Power Sources 248(7):407-415

4. Pognon G, Brousse T, Demarconnay L et al (2011) Performance and stability of electrochemical capacitor based on anthraquinone modified activated carbon. J Power Sources 196(8):4117-4122

5. Galiński M, Lewandowski A, Stępniak I (2006) lonic liquid as electrolytes. Electrochim Acta 51(26):5567-5580

6. Liu X, Shang P, Zhang Y et al (2014) Three-dimensional and stable polyaniline-grafted graphene hybrid materials for supercapacitor electrodes. J Mater Chem A 2(37):15273-15278

7. Zhang Z, Zhou Z, Peng $\mathrm{H}$ et al (2014) Nitrogen- and oxygen-containing hierarchical porous carbon frameworks for high-performance supercapacitors. Electrochim Acta 134(21):471-477

8. Torchała K, Kierzek K, Machnikowski J (2012) Capacitance behavior of $\mathrm{KOH}$ activated mesocarbon microbeads in different aqueous electrolytes. Electrochim Acta 86(4):260-267

9. Yan X, Yu Y, Yang X (2014) Effects of electrolytes on the capacitive behavior of nitrogen/phosphorus co-doped nonporous carbon nanofibers: an insight into the role of phosphorus groups. RSC Adv 4(48):24986-24990

10. Chmiola J, Yushin G, Gogotsi Y et al (2006) Anomalous increase in carbon capacitance at pore sizes less than 1 nanometer. Science 313(5794):1760-1763

11. Biener J, Stadermann M, Suss M et al (2011) Advanced carbon aerogels for energy applications. Energy Environ Sci 4(3):656-667

12. Wang Q, Yan J, Fan Z et al (2014) Mesoporous polyaniline film on ultra-thin graphene sheets for high performance supercapacitors. J Power Sources 247(2):197-203

13. Conway BE (1999) Electrochemical supercapacitors: scientific fundamentals and technological applications. Kluwer Academic/Plenum, New York

14. Liang Q, Ye L, Huang ZH et al (2014) A honeycomb-like porous carbon derived from pomelo peel for use in high-performance supercapacitors. Nanoscale 6(22):13831-13837

15. Hulicova D, Masaya Kodama A, Hatori H (2006) Electrochemical performance of nitrogen-enriched carbons in aqueous and non-aqueous supercapacitors. Chem Mater 18(9):2318-2326

16. Chmiola J, Yushin G, Dash R et al (2006) Effect of pore size and surface area of carbide derived carbons on specific capacitance. J Power Sources 158(1):765-772

17. Hulicova-Jurcakova D, Puziy AM, Poddubnaya Ol et al (2009) Highly stable performance of supercapacitors from phosphorus-enriched carbons. J Am Chem Soc 131(14):5026 
18. Oda H, Yamashita A, Minoura S et al (2006) Modification of the oxygen-containing functional group on activated carbon fiber in electrodes of an electric double-layer capacitor. J Power Sources 158(2):1510-1516
19. He Z, Liu J, Han H et al (2013) Effects of organic additives containing, $\mathrm{NH}_{2}$, and $\mathrm{SO}_{3} \mathrm{H}$ on electrochemical properties of vanadium redox flow battery. Electrochim Acta 106:556-562 